\title{
Controlled attention sharing influences time estimation
}

\author{
FRANÇOISE MACAR \\ Équipe Temps, C.N.R.S., Marseille, France \\ SIMON GRONDIN \\ Université Laurentienne, Sudbury, Ontario, Canada \\ and \\ LAURENCE CASINI \\ Équipe Temps, C.N.R.S., Marseille, France
}

\begin{abstract}
A seminal attentional model of time estimation predicts that subjective duration will be positively correlated to the amount of attention given to temporal processing. This prediction holds under prospective conditions, in which one is forewarned that judgments of time will be asked, in contrast to retrospective conditions, in which such judgments are required after the relevant period without any prior warning. In three experiments, an attention-sharing method was used. Subjects were asked to control the amount of attention that they devoted to one or the other component of a dual-task paradigm. The first experiment involved word categorization and reproduction of duration. The following experiments, based on signal detection theory, required discrimination of both the duration and the intensity of a single stimulus, in the visual (Experiment 2) or the auditory (Experiment 3) modality. The results indicate that when the attention is directly controlled by the subject, the subjective duration shortens as the amount of attention devoted to the temporal task diminishes. The implications of these results for the possible existence of an internal timer are considered.
\end{abstract}

Whether time perception relies upon specific chronometric mechanisms or is a by-product of information processing is still a matter of controversy. The data collected in the second or minute range have not always provided a consistent picture. However, the distinction made by Hicks, Miller, and Kinsbourne (1976) between prospective and retrospective judgments of time, which has by now been widely adopted (see Block, 1989; Macar, Pouthas, \& Friedman, 1992; Zakay, 1989, 1993), has tidied up a number of the inconsistencies. Under prospective conditions, subjects are forewarned that they will be requested to estimate the duration of a particular period. Under retrospective conditions, a time judgment is required after the given period, without any prior warning, and the subject's attention is directed toward other para-

The authors are grateful to Monique Chiambretto, Guy Reynard, and Stan Koren for developing the computer programs, Christophe Vallon and Lynn Metthe for their assistance in data collection, Jessica Blanc for her help with the English language, several colleagues from the Laboratory of Cognitive Neurosciences for seminal discussions on the data, and Lorraine Allan, Richard Block, and Geoffrey Loftus for their very helpful comments on the manuscript. This research was supported by Grants $911200 \mathrm{~A}$ from the Direction des Recherches et Techniques of France and 0089711 from the Natural Sciences and Engineering Research Council of Canada. Requests for reprints should be addressed to F. Macar or L. Casini, C.N.R.S., L.N.C., 31 Chemin Joseph-Aiguier, 13402 Marseille Cedex 20, France, or to S. Grondin, Université Laurentienne, Département de Psychologie, Sudbury, ON, Canada P3E 2C6. meters of the task. This distinction has helped to establish that information processing affects subjective duration differently in each case, therefore suggesting that time judgment involves different mechanisms, depending on the amount of attention devoted to the passing of time.

The retrospective method has been extensively used by Ornstein (1969) in assessing his "cognitive model" of time perception. Ornstein asked his subjects to perform various tasks, such as memorizing words or comparing geometric figures. Each item was presented for a given period and the subjects were asked to assess the duration of this period after completing the task. The subjective duration was found to increase with the quantity and the complexity of the information processed during the relevant period. According to Ornstein's metaphor, quantity and complexity determine the place occupied by information in memory-that is, the "storage size"-to which the subjective duration is directly related. In the past 20 years, studies based on the retrospective method have provided some support for Ornstein's thesis (for review, see Hicks et al., 1976, or Block, 1989, 1990).

In contrast, under prospective conditions, a large number of studies have attested that subjective duration is inversely correlated with the number of stimuli processed during the tested period (see, among others, Block, 1992; Hicks, Miller, Gaes, \& Bierman, 1977; Hicks et al., 1976; McClain, 1983; Zakay, 1989, 1993). This finding is consistent with the predictions reached by the 
models that emphasize attentional rather than memory processes in time perception studies. The first version of such attentional models was proposed by Thomas and Weaver (1975) and rests on the idea that attention is a limited-capacity system (Kahneman, 1973).

According to Thomas and Weaver (1975), the attentional resources are shared between a timer, which processes information concerning the duration, and a stimulus processor, which deals with all the other types of information and encodes the time spent processing them as well. When attention is directed toward the elapsing time, as it is under prospective conditions, time judgments will rely mainly on the output from the timer. On the other hand, when attention is focused upon the processing of nontemporal aspects of the stimulus, time judgment is based on the output from the stimulus processor. The timer is assumed to accumulate pulses as a function of time, and the subjective duration is positively correlated with the final number of pulses stored at the end of the to-be-estimated period. It is assumed that each time attention is detracted from the timer, a certain number of pulses are lost. As a result, a major prediction of this model is that the less attention given to time, the shorter the subjective duration will be.

The attentional model of Thomas and Weaver was originally devised for durations shorter than $100 \mathrm{msec}$, but it proved suitable for longer durations as well. In line with the attentional theory, Zakay (1989) suggested that the number of "subjective time units" constituting the output from the timer is erased from working memory when attention is not allocated to it in priority, so that only the output from the stimulus processor is available. This concept stresses the need for properly identifying the conditions under which either the time processor or the stimulus processor is used; attentional models should apply in the first case, and memory-based models in the second. The choice of prospective versus retrospective methods will clearly be of major importance here.

Admittedly, several aspects of the attentional models need clarification. Both types of processor certainly involve many different devices. The assumed properties of the timer have been carefully tested within the psychophysical and the animal conditioning frames (Church, 1984; Gibbon, Church, \& Meck, 1984; see Church \& Broadbent, 1990, for a connectionist description), but this is seldom explicitly mentioned within the attentional perspective. As for the pulses that are assumed to be stored, they may be viewed as chemical changes at the cell level, as spikes within neural networks, or as any other physiological event; their nature remains quite speculative. Finally, the terms attention to time or temporal information require additional specification of the parameters assumed to be processed (Block, 1990). At the least, it may be worth mentioning that these terms are not meant to suggest that time-related attributes are of peculiar essence, but, rather, are meant to stress the sim- ilarity between the mechanisms that are involved in temporal and in any other type of processing. They underline the fact that duration is one of the attributes of any stimulus, and, as such, is information and can plausibly be given either automatic or controlled attention (Michon, 1972).

Whether or not an internal timer exists is the main point of discord between the partisans of attentional and of memory-based models. The latter, who consider subjective duration to be a by-product of general information processing, reject the notion of a timer as well as that of temporal information. The former stress the need for specific timing mechanisms that can be triggered by attention. If it can be demonstrated that a certain amount of attention can be attributed to temporal as well as to nontemporal parameters and that subjective duration shortens as the amount of attention involved in temporal processing diminishes, this will reinforce the timer concept. The following experiments are a step in this direction.

The present experiments involve dual-task paradigms under prospective conditions. They were designed to manipulate attention under the subject's control; all task parameters were held constant. In this respect, they contrast with previous dual-task studies, in which the attentional effects on subjective duration were inferred from the manipulation of the quantity or the complexity of nontemporal information. Here, a method of "attention sharing" was used, which has been described in studies utilizing visual signal detection tasks (Bonnel, Possamaï, \& Schmitt, 1987; Kinchla, 1980; Sperling \& Melchner, 1978). It consists of asking a subject to allocate various proportions of attention to each component of a dual task-for example, " $80 \%$ of attention to Task $A$ and $20 \%$ to Task B" in some trials, and " $50 \%$ of attention to each" in other trials. It is assumed that the processing resources are limited and that the more attention given to one of the tasks, the better the performance in that task, at the expense of the performance in the other task. A tradeoff between the indexes of performance in each task has indeed been observed. Various types of tasks have been found to interfere after attention-sharing instructions, but no paradigm involving time judgments has been tested to date, except in our preliminary studies (Casini, Macar, \& Grondin, 1992; Grondin \& Macar, 1992).

In the following experiments, instructions specifying how attention was to be shared between temporal and nontemporal tasks were delivered prior to each trial. Two predictions, reached with the attentional model, were evaluated. (1) If the timer needs attention to function efficiently, the more attention devoted to nontemporal processing, the less accurate the temporal performance is likely to be. (2) If decreasing the amount of attention devoted to temporal processing causes the timer to miss pulses, such a decrease in attention should shorten subjective duration. The experiments differed with regard to the tasks, the durations, and/or the sensory modality involved. 


\section{EXPERIMENT 1}

In this experiment, we used a dual-task paradigm that involved word categorization and reproduction of duration. Several words appeared in succession on a video screen during a 12- or 18-sec period, according to a periodic or an aperiodic distribution pattern. The task was (1) to count animal names, and (2) to reproduce the duration of the series of words just presented by pressing a button. Two different trial durations $(12$ and $18 \mathrm{sec})$ were chosen in order to check whether the subject's accuracy would be proportional to duration (as is deduced from Weber's law) and also to minimize the possibility that the subjects would identify the duration of the word series and try to reproduce an identical duration at each trial. In fact, after the experiment, most of the subjects stated that many different trial durations had been presented; this feeling was likely due to the number of variables that changed from one trial to another. Periodic and aperiodic word distributions were mixed in order to minimize the occurrence of recurrent cues that might induce counting during a trial. Each of these factors (duration and distribution) was included in the overall analysis of variance (ANOVA) to check their possible effect on the performance indexes.

\section{Method \\ Subjects. Seventeen paid, naive volunteers ( 8 males and $9 \mathrm{fe}-$ males, aged 21 to 47 years; mean age $=27.7$ ) participated. \\ Apparatus. A microcomputer (Olivetti M300, IBM PC com- patible) was used to pilot the experiment and analyze the data. It was linked to a $26 \times 20 \mathrm{~cm}$ television display that was placed in front of the subjects. The subjects were provided with 15 buttons ( 3 ranges of 5 , with 14 black buttons numbered $1-14$ and 1 red but- ton in final position) fixated on a $23 \times 17 \mathrm{~cm}$ device. The exper- iment was conducted in a soundproof room.}

Procedure. Various series of words appeared in succession on the screen during a fixed period of either 12 or $18 \mathrm{sec}$, depending on the trials. The words were composed of between 3 and 10 letters; each word was visible for $.3 \mathrm{sec}$. They were presented either periodically, at a frequency of $1 \mathrm{~Hz}$, or aperiodically. In the latter case, the words were separated by randomly distributed intervals of $.2, .7$, or $1.2 \mathrm{sec}$ (four intervals of each duration in the 12-sec trials, and six in the 18-sec trials). The task consisted of counting animal names and/or estimating the duration of the series, the onset and offset of which were marked by a .1-sec click. The linguistic material was composed of words of several semantic categories, drawn from lists specifying their frequency of utilization in French (Dubois, 1982). Only animal names with a frequency below .53 were used so that the task would be relatively difficult. The proportion of animal names in a series varied from $8 \%$ to $56 \%$. The subjects were instructed to share their attention between the "word task" and the "duration task" in proportions that were specified on the screen, starting $7 \mathrm{sec}$ before the series onset until the end of the trial. The proportions of attention were indicated as follows: duration $100 \%$, words $0 \%$; duration $75 \%$, words $25 \%$; duration $50 \%$, words $50 \%$; words $75 \%$, duration $25 \%$; or words $100 \%$, duration $0 \%$.

Although the subjects were not expected to attribute to the task the exact percentage of attention that was specified in the instructions, the use of percentages was one simple means to suggest accurate attention sharing.
Under all these conditions, the subjects were to try to press a button for a duration that was the same as that of the series with which they had just been presented. The response was to be initiated as soon as the click marking the offset of the series had occurred. The button to be used each time was that corresponding to the number of animals counted during the series (e.g., Button 3 if three animal names were counted). The multiple-button device had two advantages. It ensured that the "duration" and "word" responses were produced simultaneously on a single support, and it enabled the subjects to perform the task without mental counting, since they could move their index finger along the buttons as the animal names appeared on the screen.

In addition to the five attention conditions, in which the subjects were required to press the appropriate button for the appropriate duration, two control conditions were designed; these were announced by the words duration only and words only. In the first case, the animal names were not to be counted, but the red button was to be pressed for the appropriate length of time. In the second case, the series duration was not to be estimated; a brief response on the button that corresponded to the number of animal names counted was required. The control conditions were expected to give us information on the cost of attention sharing under the " $100 \%-0 \%$ correct" conditions, in which the subjects probably allocated very little - but nevertheless some-proportion of attention to the secondary task, since they still had to perform it.

Each session comprised 84 trials; these were divided into three blocks, separated by 2 -min pauses. A block of 28 trials contained the seven conditions of attention $(5+2$ controls) that were run with each objective duration ( 12 and $18 \mathrm{sec}$ ) and each modality of word distribution (periodic or aperiodic). All these factors varied randomly from one trial to another. The correspondence between lists of words and each factor differed among subjects. All the words presented to a given subject were different. An intertrial interval of $7 \mathrm{sec}$ elapsed between the response offset and the onset of the next instructions.

Preliminary trials (one in each condition of attention) were run before the experiment. In these trials, the subjects practiced using the manipulandum while constantly looking at the screen.

\section{Resuits}

Two indices were submitted to an ANOVA: (1) the time error percentage - that is, the difference between the duration produced and the target duration divided by the target duration (e.g., a $10 \%$ error corresponds to a difference of $1.2 \mathrm{sec}$ in the 12-sec duration), and (2) the word error percentage, or the difference between the animal names counted and the total to be counted, divided by the latter.

Figure 1 shows the time error and word error percentages under the five attention-sharing conditions and the control conditions. Durations (12 and $18 \mathrm{sec}$ ) and word distributions (periodic and aperiodic) are pooled together (they are presented separately for time errors in Figure 2). The negative signs indicate that the duration and number of animal names were underestimated. The time error percentage steadily increased as the proportion of attention devoted to duration diminished. When $100 \%$ attention was paid to duration, an error of $-7 \%$ was obtained; $-21 \%$ was obtained when $100 \%$ attention was paid to words. The error was markedly reduced $(-1 \%)$ under the duration-only condition, which did not require any response to words. The opposite pattern was ob- 


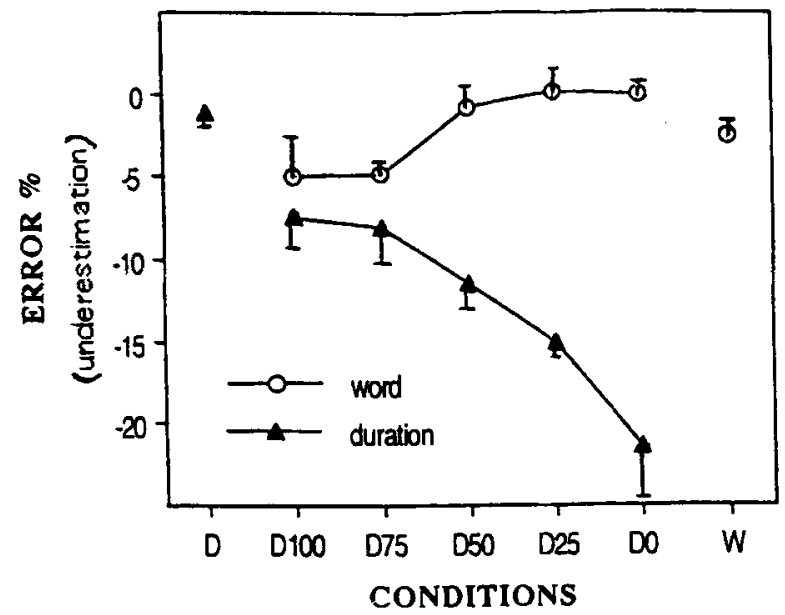

Figure 1. Mean percentage of errors in the duration and word tasks as a function of attention-sharing and control conditions in Experiment 1 (error bars are confidence limits at the .05 level). Shown are interindividual data for 17 subjects. The negative signs on the ordinate illustrate underestimations in subjective duration or in the number of animal names counted. On the abscissa, D100-D0 refer to the proportions of attention allocated to duration (D, duration only; $\mathbf{w}$, word only).

served with the percentages of word errors, which tended to decrease when larger proportions of attention were attributed to words. Note that the time and word errors have been presented within the same figure in order to facilitate observation of the interference effects, but that the two performance-rating indexes are not homogeneous. Among other differences, time error is a continuous index, whereas word error is a discrete one.

Since subjective duration decreased with the amount of attention devoted to time, the intrasubject variability globally presented the same trend. Within-subjects standard deviations averaged over subjects in the 12- and 18sec durations and pooled together were, respectively, $3.69,3.24,2.82,2.98,2.62$, and 3.05 from the durationonly to the $0 \%$-duration conditions (note that the latter condition nevertheless induced a relatively large variability). No systematic trend was observed when the coefficient of variation was calculated by dividing the variability measure by the mean subjective duration obtained under each condition $(.16, .19, .15, .17, .18$, and .18 , respectively, from the duration-only to the $0 \%$ duration conditions).

Figure 2 shows the time error percentage as a function of duration and word distribution under the attentionsharing and control conditions. Under all conditions, underestimation was more marked in the 18-sec than in the 12-sec duration.

An ANOVA was carried out on time error and word error percentages according to a randomized block factorial (RBF) design to test the effect of conditions on attention sharing (5), duration (2), and word distribution (2) in the 17 subjects. Note that in Experiments 1-3, $F$ values were considered significant at $p<.05$. The time errors were affected by attention sharing $[F(4,64)=9.07$, $\left.M S_{\mathrm{e}}=1.56, p<.001\right]$ and duration $[F(1,16)=89.49$, $\left.M S_{\mathrm{e}}=1.38, p<.001\right]$, but not by word distribution $\left[F(1,16)=3.53, M S_{\mathrm{e}}=1.67\right]$. With the word errors, only the attention-sharing factor $[F(4,64)=2.51$, $\left.M S_{\mathrm{e}}=1.25, p<.05\right]$ yielded significant differences [duration, $F(1,16)=.02, M S_{\mathrm{e}}=.65$; word distribution, $\left.F(1,16)=1.28, M S_{\mathrm{e}}=1.19\right]$. Neither time nor word errors showed any significant interactions between factors.

The control conditions, which involved only one response, were compared with the $100 \%-0 \%$ conditions, in which the secondary response was required to be performed with minimal attention. The ANOVA on the time error percentage showed a significant effect of condition $\left[F(1,16)=5.18, M S_{\mathrm{e}}=1.35, p<.05\right]$, duration $\left[F(1,16)=10.97, M S_{\mathrm{e}}=.88, p<.01\right]$, and word distribution $\left[F(1,16)=13.81, M S_{\mathrm{e}}=1.19, p<.01\right]$. With the word error percentage, no significant differences were found [condition, $F(1,16)=.37, M S_{\mathrm{e}}=1.09$; duration, $F(1,16)=1.59, M S_{\mathrm{e}}=.90 ;$ word distribution, $F(1,16)=$ $\left..03, M S_{\mathrm{e}}=.97\right]$. Neither time nor word errors showed any significant interactions between factors.

When the subjects were questioned after the experiment, they reported that they had not counted during the trials, in accordance with the instructions. Most of them were convinced that all the trial durations had been different, which confirms that the factors had strong effects on subjective duration.

\section{Discussion}

Interference effects were found between duration and word tasks under the conditions used in this experiment. The attention-sharing instructions had consequences on

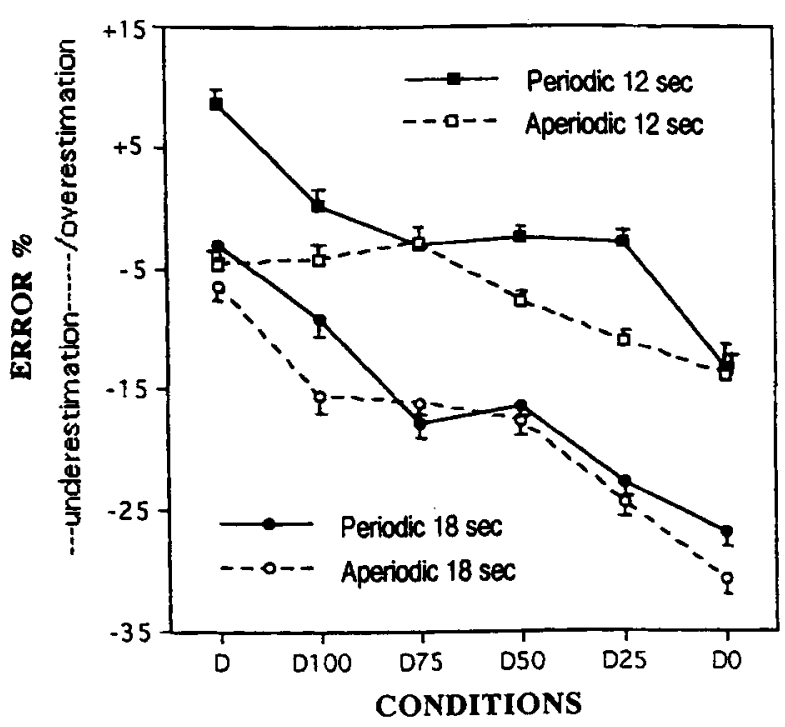

Figure 2. Mean percentage of errors in the 12- and 18-sec durations as a function of attention-sharing and control conditions in Experiment 1 (error bars are confidence limits at the .05 level). Shown are interindividual data for 17 subjects. Same symbols as in Figure 1 on the abscissa. The positive and negative signs on the ordinate illustrate underestimations and overestimations, respectively. 
the performance with regard to both components of the dual-task paradigm.

Interference effects have generally been interpreted as indications that the two types of processing operations share a common pool of attentional resources with a limited capacity (e.g., Kahneman, 1973; Kramer \& Spinks, 1991). The notion of resources refers to "the processing facilities available to a system for performing its functions" (Norman \& Bobrow, 1976, p. 508). The model of limited capacity implies that the more capacity required for one task, the less spare capacity will be left over for the other one, and thus the level of performance on this second task will be lower. For instance, there is evidence that orienting attention to spatial locations and to linguistic items depends on a unified system, despite the admittedly quite separate nature of the tasks (Posner \& Petersen, 1990). Studies of patients with lesions have revealed the existence of hemispheric differences that suggest, however, that separate but interconnected attentional systems are at work (Posner, Inhoff, Friedrich, \& Cohen, 1987). Alternative hypotheses have also been proposed (Navon \& Gopher, 1979). The present attentionsharing procedure was not selected in hopes of deciding between these concepts, but, rather, as a straightforward means of checking whether the amount of attention paid to temporal processing can be controlled by the subject on the basis of specific instructions. Evidence for control of this kind was yielded by the results of Experiment 1 . This provides support for the attentional hypothesis, whereby an efficient functioning of the timer subserving time estimation judgments requires attentional resources. When time estimation constitutes a critical aspect of performance, temporal processing is not a by-product of other processing operations. Here, the attention is focused on the relevant temporal parameters instead, and specific chronometric mechanisms may be activated. The storage-size theory views nontemporal information processing as the sole determinant of subjective duration, and therefore it does not help to account for the present data.

Another argument in favor of the attentional model centers on the positive relationship that was found to exist here between subjective duration and the amount of attention allocated to the duration task. The underestimations became more and more pronounced from the duration-only to the $0 \%$-attention-to-duration conditions. If a timer does exist, it can be assumed to collect pulses during the period to be estimated. The less attention paid to temporal processing, the more pulses will be lost, whether the pulses are simply not recorded by the counter or are subsequently erased from it. As a result, subjective duration shortens, since it depends on the number of pulses that constitute the output of the counter.

Although time judgments might be thought to become more variable when little attention is paid to time (Thomas \& Weaver, 1975), the present data do not support this expectation. As discussed by Block (1992), the variability issue remains unclear, since it has yielded inconsistent data. It seems to be clearer in dual or multi- ple tasks that include only temporal components: Variability does increase when the subject's attention is devoted to several durations simultaneously, rather than to one duration (Brown, Stubbs, \& West, 1992; Brown \& West, 1990).

The fact that the percentage of time errors was relatively higher in the 18- than in the 12-sec durations under all conditions reveals information about the timer. A timer can be interpreted as a clock-counter or pacemakeraccumulator system. In the psychophysics literature regarding time, the rate of the pacemaker is sometimes assumed to be constant (Allan, Kristofferson, \& Wiens, 1971; Creelman, 1962) and is sometimes considered to be variable (Divenyi \& Danner, 1977; Fetterman \& Killeen, 1991; Treisman, 1963). With a constant rate, the time errors should be a constant proportion of the target duration. Our results do not conform to this view. Rather, they argue in favor of a pacemaker with a variable frequency, or rule out the idea of a single pacemaker.

The time errors were clearly more sensitive than the word errors to the experimental manipulations. First, the aperiodic word distribution, compared with the periodic one, increased the time error, but not the word error, under the control and $100 \%-0 \%$ conditions. The same trend appeared under the other conditions, but it was not significant at the $p<.05$ level. The subjects mentioned that although they did not count seconds, they were able to estimate time more easily when periodic cues were delivered. This effect has been found in other studies (Jones \& Boltz, 1989; Macar, 1994). Second, subjective duration was affected when even very small amounts of attention were diverted to the rival word task, whereas the word errors did not vary from the word-only to the word- $50 \%$ conditions (see Figure 1). Third, a concurrence cost was found to exist in the duration task, but not in the word task. This cost, as estimated from the deficit in the duration- $100 \%$ as compared with the durationonly conditions, implies that part of the attentional resources must be allocated to monitoring the actual sharing (Navon \& Gopher, 1979) and preparing two responses. The results suggest that the attentional cost detracted from the resources devoted to time, but not to words.

There were several possible reasons for this inequality in sensitivity between time and word performances. As underlined by Thomas and Cantor (1978), when there are interference effects between temporal and nontemporal components in a task, the nontemporal information is given priority. The typically high sensitivity of temporal tasks to interference factors may reflect the fact that it is difficult to direct one's attention to timerelated cues that are possibly of internal origin, contrary to what happens with external and more obvious nontemporal signals. The latter signals likely induce automatic attending, even when controlled attention is also required. Moreover, the contrast between the temporal and nontemporal requirements was perhaps enhanced by the relative easiness of the particular word task used. Although the subjects stated that this task was fairly difficult under the attention-sharing conditions because 
some of the animal names were not part of everyday usage, the sensitivity of the word task to interference would probably have increased had the material been chosen to induce a larger error rate, even under the control conditions. As already noted, another limitation of the procedure arose from the fact that the error rate was a continuous index in the time conditions and a discrete index in the word conditions. The following experiments were designed to overcome these limitations and verify whether attention-sharing effects can also be found with different tasks and different duration ranges.

\section{EXPERIMENT 2}

In Experiment 2, a discrimination task involving signal duration and signal intensity was chosen. The $d^{\prime}$ index drawn from the signal detection method (Tanner \& Swets, 1954) was used to provide equivalent measures of sensitivity to the temporal and the nontemporal components of this dual task. The $d^{\prime}$ index is thought to reflect the subject's sensory response to a signal, independently of changes in decision processes or response bias. It is suited to the measurement of attentional effects supposed to take place at an early stage of information processing.

\section{Method}

Subjects. Sixteen subjects ( 8 males and 8 females, aged 19 to 27 years) took part in this experiment. Each subject performed three sessions.

Apparatus. The subjects were placed in a dimly lit, soundshielded room. They were seated facing a video screen, on which a green light appeared with variable duration and intensity. Their fingers were placed on 10 response keys. The experiment was piloted and the data were collected with a microcomputer (HewlettPackard Vectra QS 165).

Procedure. A visual stimulus (green light) appeared on the screen with either a strong or a weak intensity for either a short or a long duration, depending on the trial. The subjects were to identify both intensity and duration. One second prior to stimulus presentation, instructions lasting $5 \mathrm{sec}$ and specifying how attention was to be shared between the two tasks were presented on the screen. There were three conditions of attentional sharing: maximum duration/minimum intensity, maximum intensity/minimum duration, and half/half. In all these conditions, the subject gave two judgments; one corresponded to duration (with one hand) and one corresponded to intensity (with the other one). The correspondence between judgment and hand was balanced interindividually. Depending on the hand, the thumb and the little finger corresponded either to short and long (duration) or to weak and strong (intensity), respectively. After each of these responses, the subject indicated his/her level of confidence. Three levels were available: very sure, almost sure, and unsure, corresponding, respectively, to a pressure of the index finger, middle finger, and ring finger of each hand. Therefore, four responses (two with each hand) were registered. Two other (control) conditions corresponded to a single task: duration only or intensity only. In either case, only two responses were given: one for the judgment on duration or intensity and one for the confidence level.

Each subject took part in three sessions (in counterbalanced order) in which distinct duration ranges were tested. The short and long durations were: (1) 350 and $650 \mathrm{msec}$ (mid-duration $=500 \mathrm{msec}$ ), (2) 1,250 and 1,750 msec (mid-duration $=1,500 \mathrm{msec}$ ), and (3) 2,500 and 3,500 msec (mid-duration $=3,000 \mathrm{msec}$ ). The in- tensities were $1.5 \mathrm{mcd}$ (weak) and $2.25 \mathrm{mcd}$ (strong) in all sessions. Constant median values were used for intensity $(1.875 \mathrm{mcd})$ under the duration-only condition and for duration $(500,1,500$, or $3.000 \mathrm{msec}$ in Sessions 1,2 , or 3 ) under the intensity-only condition.

Each session contained 400 trials, which were separated into five blocks of 80 trials. A block consisted of 16 different stimulus combinations ( 3 conditions of attention sharing $\times 2$ durations $\times$ 2 intensities +4 control conditions: short duration, long duration, weak intensity, strong intensity); each was presented five times. All trials were delivered randomly.

Prior to the experiment, the subjects were given a training session divided into two parts in counterbalanced order: intensity training (A) and duration training (B). The first step involved five presentations of a pair of stimuli: weak-strong in Part $A$ and short-long in Part B (with separate training in the 500-, 1,500-, and 3,000-msec durations in counterbalanced order). Intervals of $1 \mathrm{sec}$ within a pair and of $2 \mathrm{sec}$ between pairs were used. In a second step, the subject performed 20 trials ( 10 weak and 10 strong in Part A; 10 short and 10 long in Part B, randomly distributed) with 5-sec intertrial intervals. Results (the words right or wrong appeared on the screen) were provided immediately after each response. In a third step, there were 50 trials ( 25 and 25 ) without display of results. The subject's performance in each single task, measured in this set of 50 trials and preceding the experimental session, was called "out-control" (OC), to distinguish it from the "in-control" performance (D or I) obtained in each single task during the experimental session. In preliminary sessions, the stimulus parameters were chosen to yield $70 \%$ to $90 \%$ correct judgments in the single-task conditions.

\section{Results}

Two indices were calculated in each task:

1. The index of sensitivity from the signal detection theory was calculated to observe the effect of attentional sharing on the subject's sensitivity. This index was calculated on the basis of a $z$ transformation of the probabilities of responding "long" (hits) and "short" (false alarms) in the duration task when the signal was long (or "strong" and "weak" in the intensity task when the signal was strong). The index $d^{\prime}$ was compared with $d^{\prime} e$, based on the receiver operating characteristic (ROC) curves computed with the three confidence levels. Similar values were obtained, since the normal/normal slopes of the ROC curves were approximately equal to 1 (the distributions of "short" and "long" or "weak" and "strong" responses were of equal variance). Therefore, confidence levels were not required in the next experiment and only $d^{\prime}$ measures are reported below.

2. The percentage of "short" responses in the duration task (or "weak" in the intensity task) relative to the total number of responses was calculated to observe the effect of attention on subjective duration (or on subjective intensity). An inverse relationship between the percentage of "short" responses and the amount of attention devoted to the duration task was expected, in line with the attentional hypothesis. No prediction was done regarding the percentage of "weak" responses.

ANOVAs were performed on these indices according to an RBF design. For the $d^{\prime}$ indices, a first analysis included 16 subjects $(S) \times 3$ durations (D) $\times 3$ attentionsharing conditions (A). A second included 16 subjects $\times 3$ durations $\times 2$ control conditions (OC and D or I). 
For the percentage of "short" responses, the analysis included 16 subjects $\times 3$ durations $\times 3$ attention-sharing conditions $\times 2$ intensities of the stimulus (I). For the percentage of "weak" responses, it comprised 16 subjects $\times 3$ durations $\times 3$ attention-sharing conditions $\times$ 2 durations of the stimulus (SD).

Sensitivity: $d^{\prime}$ index. Figure 3 shows the $d^{\prime}$ index as a function of the attention-sharing conditions in the intensity and duration tasks for the 500-, 1,500-, and 3,000-msec durations.

In the duration task, the results of the first ANOVA showed a significant effect of duration $[F(2,30)=13.47$, $\left.M S_{\mathrm{e}}=.93, p<.01\right]$ and attention sharing $[F(2,30)=8.27$, $\left.M S_{\mathrm{e}}=.50, p<.01\right]$ and no significant interaction $\left[F(4,60)=2.49, M S_{\mathrm{e}}=.55\right]$. In all duration ranges, the $d$ 'index decreased as less attention was devoted to duration. The ANOVA on control conditions revealed an effect of duration and condition $\left[F(2,30)=5.38, M S_{\mathrm{e}}=\right.$ $.38, p<.01$, and $F(1,15)=9.01, M S_{\mathrm{e}}=.31, p<.01$, re-

$500 \mathrm{msec}$

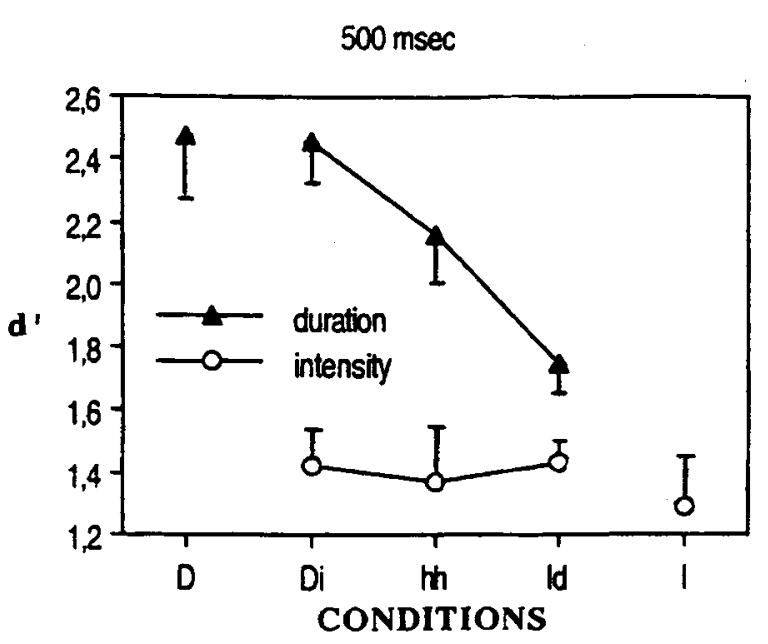

spectively] and no interaction $\left[F(2,30)=1.99, M S_{\mathrm{e}}=\right.$ .33]. The mean $d^{\prime}$ index under Condition $\mathrm{D}(2.26)$ was inferior to the one obtained under OC (2.63).

In the intensity task, there was an effect of duration $\left[F(2,30)=6.70, M S_{\mathrm{e}}=.96, p<.01\right]$. Figure 3 suggests that an increase in duration improved discrimination. There was no effect of attention sharing $[F(2,30)=2.90$, $\left.M S_{\mathrm{e}}=.64\right]$, although the $d^{\prime}$ indices seemed to decrease when less attention was devoted to intensity. No interaction appeared between duration and attention sharing $\left[F(4,60)=1.56, M S_{\mathrm{e}}=.48\right]$. The ANOVA on control conditions showed a significant effect of duration $[F(2,30)=$ $\left.5.62, M S_{\mathrm{e}}=.31, p<.01\right]$, no effect of condition $[F(1,15)=$ $\left.0.54, M S_{\mathrm{e}}=.33\right]$, and no interaction $[F(2,30)=0.86$, $\left.M S_{\mathrm{e}}=.32\right]$.

Percentage of "short" responses. Figure 4 shows the evolution of the percentage of "short" responses as a function of the attentional sharing in each duration range. This percentage increased with the amount of attention

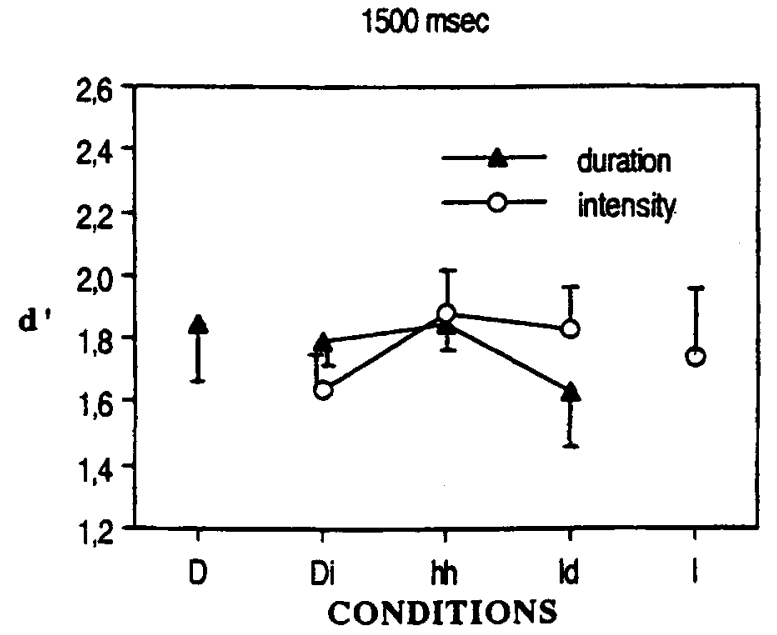

$3000 \mathrm{msec}$

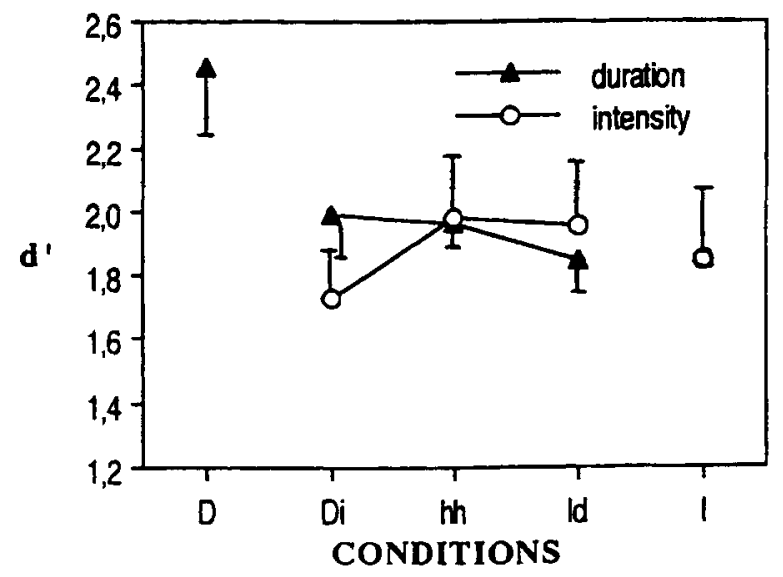

Figure 3. Performance levels $\left(d^{\prime}\right)$ in the duration and intensity tasks as a function of attention-sharing and control conditions in Experiment 2 (error bars are confidence limits at the , 05 level, with $20 \%$ reduction). Shown are 500-, 1,500-, and 3,000-msec durations; interindividual data are for 16 subjects. On the abscissa, D, Di, hh, Id, and I refer to duration only, maximum duration/minimum intensity, half/half, maximum intensity/minimum duration, and intensity only, respectively. 


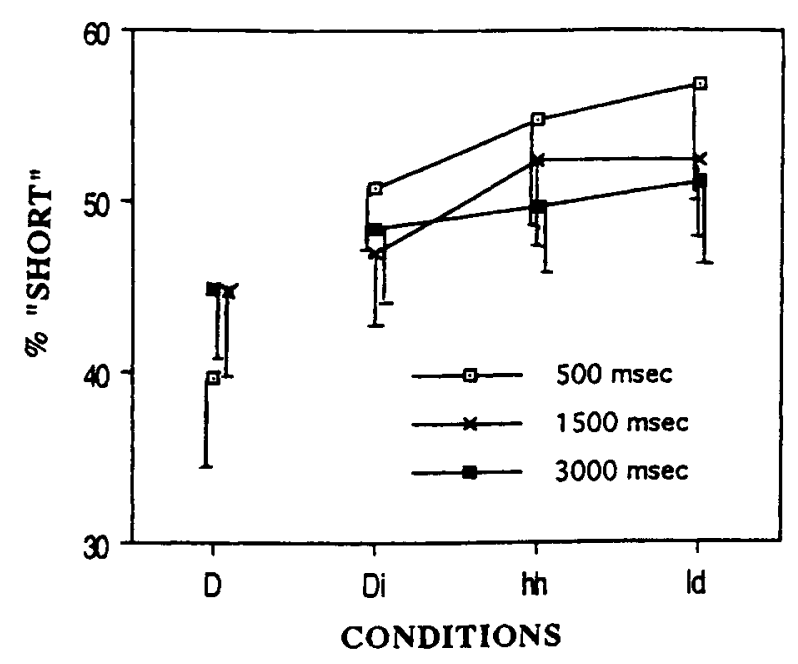

Figure 4. Percentage of "short" responses in each duration range as a function of the attention-sharing conditions in Experiment 2 (error bars are confidence limits at the .05 level). Shown are interindividual data for 16 subjects. Same symbols as in Figure 3 on the abscissa.

allocated to the identification of intensity. The ANOVA revealed a significant effect of attention sharing $[F(2,30)=$ $\left.6.85, M S_{\mathrm{e}}=1.11, p<.001\right]$. There was also an effect of intensity $\left[F(1,15)=5.80, M S_{\mathrm{e}}=.74, p<.05\right]$; when "short" responses were given, $50.8 \%$ were induced by the strong intensity and $52.2 \%$ were induced by the weak one. There was no effect of duration $[F(2,30)=1.21$, $\left.M S_{\mathrm{e}}=2.55\right]$ and no interaction $[\mathrm{D} \times \mathrm{A}, F(4,60)=0.81$, $M S_{\mathrm{e}}=.89 ; \mathrm{D} \times \mathrm{I}, F(2,30)=0.84, M S_{\mathrm{e}}=.80 ; \mathrm{A} \times \mathrm{I}$, $\left.F(2,30)=2.38, M S_{\mathrm{e}}=.73\right]$.

Percentage of "weak" responses. With duration ranges pooled together, $44.4 \%, 47.7 \%$, and $47.5 \%$ of "weak" responses were produced, respectively, under the maximum, half, and minimum-attention-to-intensity conditions. The ANOVA performed on this index showed a significant effect of attention sharing $[F(2,30)=4.97$, $\left.M S_{\mathrm{e}}=1.03, p<.01\right]$, no effect of duration range $[F(2,30)=$ $\left.1.67, M S_{\mathrm{e}}=1.62\right]$ or of stimulus duration $[F(1,15)=0.68$, $\left.M S_{\mathrm{e}}=.78\right]$, and no interaction $[\mathrm{D} \times \mathrm{A}, F(4,60)=1.32$, $M S_{\mathrm{e}}=.88 ; \mathrm{D} \times \mathrm{SD}, F(2,30)=2.09, M S_{\mathrm{e}}=.72 ; \mathrm{A} \times \mathrm{SD}$, $\left.F(2,30)=1.30, M S_{\mathrm{e}}=.71\right]$.

\section{Discussion}

In visual signal detection tasks in which the method of attention sharing has been elaborated (Kinchla, 1980; Sperling \& Melchner, 1978), subjects pay attention to two different stimuli presented together, but located separately. The results from the present Experiment 2 suggest that attention may also be shared between two different aspects of the same stimulus. The data are not entirely conclusive, since the effect of attention sharing was significant in the duration but not in the intensity task. Nevertheless, the $d^{\prime}$ indexes tended to have an evolution that was opposite in the two tasks (see Figure 3), and this points to the possibility of interference effects at an early processing stage. The decrement in the ca- pacity of discriminating durations when less attention is allocated to time suggests that time estimation uses up attentional resources like any other type of information processing. This finding is consistent with the results of Experiment 1 and may again be interpreted in the framework of the attentional model.

The level of performance in each task was found to vary as a function of the duration range. The longer the duration, the better the intensity discrimination. This can be simply explained, considering that the information concerning intensity was available for a longer time. In the duration task, only the 3,000-and 1,500-msec ranges can be compared, because in these ranges the gap between the two durations to be discriminated was a constant proportion (one third) of the mid-duration. An analysis of contrasts indicated that the duration discrimination was better with 3,000 than with $1,500 \mathrm{msec}$ $\left[F(1,15)=9.42, M S_{\mathrm{e}}=.55, p<.01\right]$. Thus, with the longest duration ranges, Weber's law was disclaimed. The gap was larger in the $500-\mathrm{msec}$ range, which produced the highest level of temporal discrimination. Note that the gap was chosen to produce good (but not perfect) and roughly equivalent levels of performance between the duration and the intensity tasks. The required performance levels were determined in preliminary trials involving each task separately. Since the attentionsharing conditions could influence the $d^{\prime}$ index differently in each task and each duration, this index was finally found to be more similar between tasks in certain duration ranges than in others.

The significant difference found between the two types of control conditions in the duration but not in the intensity discrimination may indicate that the temporal task was very sensitive to the attention-sharing context. To modify, at each trial, the amount of attention allocated to each task, a large amount of attentional resources may be needed; this would be sufficient to damage the temporal performance under the duration-only condition, because the processing of duration is itself very demanding. Such data again sustain those of Experiment 1, which pointed to a higher sensitivity of the duration task than of the word task.

The increase in the percentage of "short" responses obtained when attention was allocated in priority to the intensity task reveals a decrease in subjective duration, consistent with the timer model. According to the hypothesis that proposes that a timer accumulates pulses during the duration to be identified, a decrease in subjective duration suggests that a certain quantity of pulses might be lost when attention is detracted from time (Meck, 1984; Rousseau, Picard, \& Pitre, 1984). Therefore, each time attentional priority was given to the intensity processor, pulse storage may have stopped or may have been impaired, thus reducing the final number of pulses available in the counter.

Finally, two aspects of the present data raise questions in relation to the processing of visual intensity. First, the negative relationship observed in the duration task between the number of "short" responses and stimulus in- 
tensity indicates that duration estimation is not entirely independent of nontemporal parameters. Such a relationship between intensity and duration has often been found in psychophysical studies with stimulus durations shorter than $1,000 \mathrm{msec}$ (for review, see Allan, 1979, or Macar, 1980, 1985). The present experiment extends this result to stimuli as long as $3,500 \mathrm{msec}$. Second, in the intensity task, the percentage of "weak" responses increased when the attention allocated to the intensity task decreased. This finding strengthens the idea that the method of attentional sharing used here was efficacious, but raises problems with regard to the processing of stimulus intensity. The reason why a visual cue would be perceived as brighter when the subject's attention focuses on it is unclear.

\section{EXPERIMENT 3}

The next question was whether the attentional effects found with the visual discrimination task would also appear in a different modality and with a shorter duration $(250 \mathrm{msec})$, closer to the duration range in which Thomas and Weaver (1975) originally elaborated their model. In Experiment 3, the nontemporal task was a discrimination of the intensity of auditory signals. For direct comparison with Experiment 2, the longest stimulus duration used was $3,000 \mathrm{msec}$.

\section{Method}

Subjects. Sixteen volunteers ( 7 males and 9 females, aged 21 to 32 years) participated in this experiment.

Apparatus. The subjects were seated in a chair in a dimly lit room and were asked to respond with the appropriate pushbutton. On one panel, one button corresponded to "short" responses and another corresponded to "long" responses. On another panel, two pushbuttons corresponded - one to the weak intensity and one to the strong intensity. The auditory stimulation was a $1-\mathrm{kHz}$ sound delivered binaurally via headphones. During the training blocks of 20 trials, the feedback after each trial was delivered by one of two small lights on each panel. The one beside the left pushbutton corresponded to "short" or "weak," and the one beside the right one corresponded to "long" or "strong." The sequence of presentation of stimuli and the collection of data were controlled by an IBM microcomputer.

Procedure. In each trial, a subject was to render one or two judgments of duration and auditory intensity, according to the current condition. The task was to decide whether the auditory signal was short or long, and weak or strong. In one session, the short duration lasted $230 \mathrm{msec}$ and the long duration lasted $270 \mathrm{msec}$ (mid-duration $=250 \mathrm{msec}$ ). In the other session, the short duration lasted $2,760 \mathrm{msec}$ and the long duration lasted $3,240 \mathrm{msec}$ (mid-duration $=3,000 \mathrm{msec}$ ). In both sessions, the difference between the weak and strong intensities was less than $1.5 \mathrm{~dB}$ with a mid-intensity of $70 \mathrm{~dB}$.

The rest of the procedure - the different conditions, the number of trials and blocks, the counterbalancing of conditions within each block, and the training session-was as described in Experiment 2, except that, as indicated previously, no measure of confidence levels regarding the response was taken, in order to alleviate the subject's mental load.

\section{Results}

As in Experiment 2, two dependent variables were analyzed for both tasks: The performance levels $\left(d^{\prime}\right)$ and the percentage of "short" (duration task) or "weak" (intensity task) responses.

Sensitivity: $d^{\prime}$ index. Figure 5 shows the $d^{\prime}$ index as a function of the attention-sharing conditions in the duration and intensity tasks for the 250 - and 3,000-msec durations.

In the duration task, the ANOVA that was performed according to an $\mathrm{RBF}$ design (2 durations $\times 3$ attentionsharing conditions) revealed no effect of duration $\left[F(1,15)=2.07, M S_{\mathrm{e}}=.16\right]$, an effect of attention $\left[F(2,30)=6.61, M S_{\mathrm{e}}=.08, p<.01\right]$, and no interaction $\left[F(2,30)=.98, M S_{\mathrm{e}}=.09\right]$. The worst performances were observed when minimum attention was allocated to duration. The duration-only condition (D) was compared with the out-control condition (OC); an ANOVA
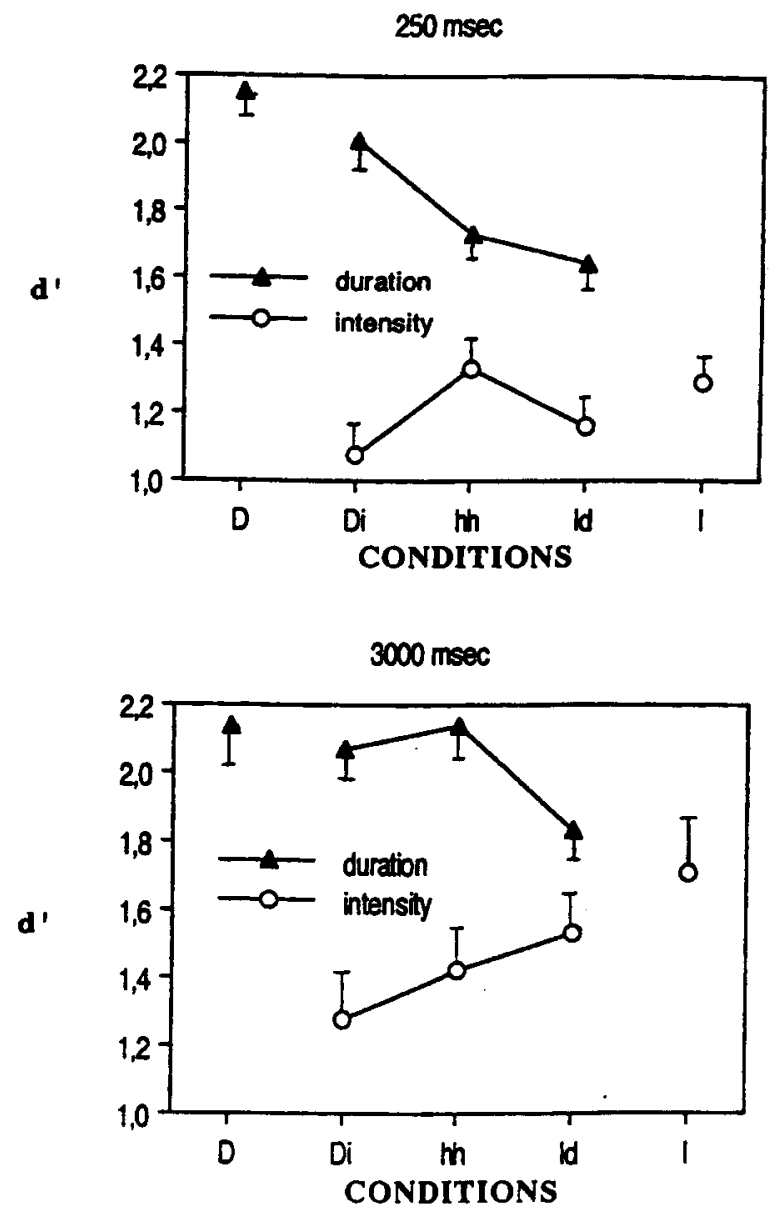

Figure 5. Performance levels $\left(d^{\prime}\right)$ in the duration and intensity tasks as a function of the attention-sharing conditions in Experiment 3 (error bars are confidence limits at the .05 level, with $20 \%$ reduction). Top, 250-msec duration; bottom, 3,000-msec duration. Shown are interindividual data for 16 subjects. Same symbols as in Figure 3 on the abscissa. 
( 2 durations $\times 2$ conditions) revealed no significant differences [duration, $F(1,15)=.22, M S_{\mathrm{e}}=.19$; condition, $F(1,15)=3.61, M S_{\mathrm{e}}=.12 ;$ interaction, $F(1,15)=.35$, $\left.M S_{\mathrm{e}}=.15\right]$.

In the intensity task, none of the effects of the 2 (duration) $\times 3$ (attention) design ANOVA were significant [duration, $F(1,15)=1.88, M S_{\mathrm{e}}=.22$; attention, $F(2,30)=$ $2.75, M S_{\mathrm{e}}=.07$; interaction, $\left.F(2,30)=.59, M S_{\mathrm{e}}=.07\right]$. The $2 \times 2$ ANOVA for comparing the intensity and outcontrol conditions showed no significant differences [duration, $F(1,15)=1.52, M S_{\mathrm{e}}=.08$; condition, $F(1,15)=$ $.34, M S_{\mathrm{e}}=.12$; interaction, $\left.F(1,15)=.74, M S_{\mathrm{e}}=.11\right]$.

Percentage of "short" responses. As illustrated in Figure 6, there were differences in the percentage of "short" responses in the duration task. A $2 \times 2 \times 3$ ANOVA conducted with an RBF design that included the fact that the signal was weak or strong (i.e., intensity factor, or I) revealed an effect of duration $[F(1,15)=$ $\left.36.13, M S_{\mathrm{e}}=2.21, p<.01\right]$ and of attention $[F(2,30)=$ $\left.4.80, M S_{\mathrm{e}}=2.13, p<.05\right]$, but no effect of intensity $\left[F(1,15)=.03, M S_{\mathrm{e}}=1.37\right]$. The interaction between attention and duration was significant $[F(2,30)=3.93$, $\left.M S_{\mathrm{e}}=1.79, p<.05\right]$; only in the 250 -msec duration was the percentage of "short" responses higher when less attention was given to duration. No other interaction was found [D $\times \mathrm{I}, F(1,15)=.47, M S_{\mathrm{e}}=1.62 ; \mathrm{A} \times \mathrm{I}$, $F(2,30)=2.62, M S_{\mathrm{e}}=1.42 ; \mathrm{A} \times \mathrm{D} \times \mathrm{I}, F(2,30)=.63$, $\left.M S_{\mathrm{e}}=1.42\right]$.

Percentage of "weak" responses. In the intensity task, a $2 \times 2 \times 3$ ANOVA performed on the percentage of "weak" responses, which included the fact that the stimulus was short or long within each duration range (stimulus duration factor, or SD), revealed no effect of duration range $\left[F(1,15)=4.35, M S_{\mathrm{e}}=3.89\right]$ or of attention $\left[F(2,30)=1.16, M S_{\mathrm{e}}=2.38\right]$, but an effect of stimulus duration $\left[F(1,15)=15.37, M S_{\mathrm{e}}=1.69, p<.01\right]$. Only the

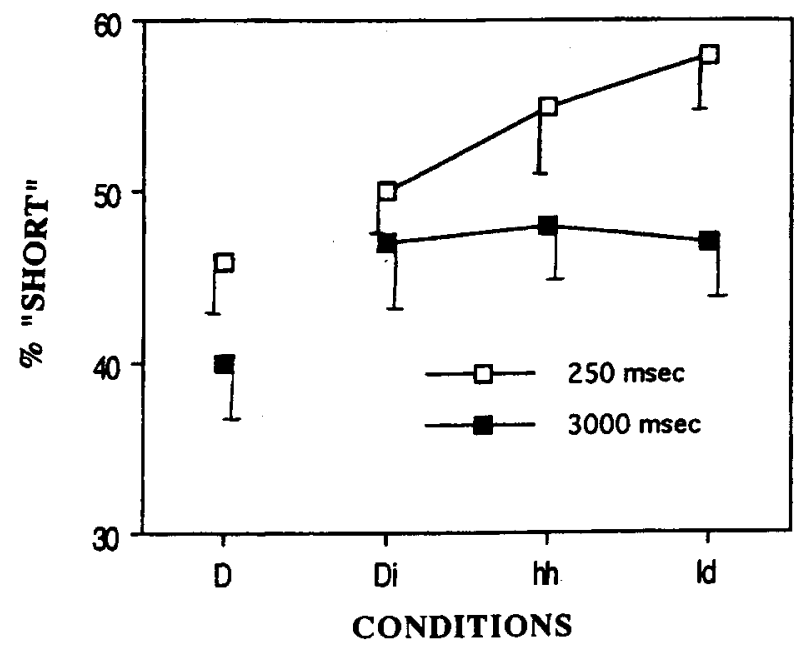

Figure 6. Percentage of "short" responses in each duration range as a function of the attention-sharing conditions in Experiment 3 (error bars are confidence limits at the .05 level). Shown are interindividual data for 16 subjects. Same symbols as in Figure 3 on the abscissa. interaction between attention and stimulus duration was significant $\left[\mathrm{A} \times \mathrm{SD}, F(2,30)=5.22, M S_{\mathrm{e}}=1.69, p<\right.$ $.05 ; \mathrm{D} \times \mathrm{A}, F(2,30)=.06, M S_{\mathrm{e}}=2.29 ; \mathrm{D} \times \mathrm{SD}$, $F(1,15)=.70, M S_{\mathrm{e}}=1.73 ; \mathrm{A} \times \mathrm{D} \times \mathrm{SD}, F(2,30)=1.38$, $\left.M S_{\mathrm{e}}=1.60\right]$. The percentage of "weak" responses was lower with the long stimulus than with the short stimulus when the proportion of attention allocated to intensity was maximal ( $45.7 \%$ for long vs. $52.4 \%$ for short) and half ( $43.8 \%$ for long vs. $49.1 \%$ for short), but not minimum ( $48.2 \%$ for long vs. $47.6 \%$ for short).

\section{Discussion}

In general, the results of Experiments 2 and 3 are congruent. In the duration task, whether the relevant durations correspond to auditory or visual stimuli, the capacity to discriminate them is sensitive to the manipulation of attention. Also, the probability of judging a duration to be short or long is related to the amount of attention devoted to time. In the intensity task, neither Experiment 2 nor 3 yielded a significant effect of attention sharing on the $d^{\prime}$ index. Thus, the intensity task appears to be less sensitive to the attention factor than the duration task.

These results also strengthen the data obtained in two preliminary studies, in which the signal detection method was used with auditory signals centered on 500 and $1,500 \mathrm{msec}$ (Grondin \& Macar, 1992) and visual signals centered on 1,500 and 3,000 msec (Casini et al., 1992). Despite differences in the procedures (i.e., the gap within the pair of durations to be discriminated in a session was different between the two visual studies, and this induced different performance levels; the subjects were asked to give levels of confidence in Grondin and Macar's auditory study, but not in Experiment 3; and different duration ranges were tested in the latter two works), the main trends found in this set of experiments involving double discrimination are consistent.

Interestingly, in the auditory modality, the effect of attention on subjective duration appeared with only brief duration ranges. "Short" responses were more frequent when attention to time diminished in the ranges of 250 (Experiment 3) and 500 (Grondin \& Macar, 1992), but not 1,500 (Grondin \& Macar, 1992) and 3,000 msec (Experiment 3 ). This may indicate that the key factor is the time spent processing intensity, relative to the stimulus duration. A few subjects mentioned that they had judged intensity as soon as the signal had been presented. Possibly, the subjects' attention was first automatically applied to the intensity and was directed toward the discrimination of duration only after the intensity had been processed. Since the time spent processing intensity was proportionally longer in the shortest signal durations, this may explain why subjective duration was influenced only in those durations.

Judgments on intensity were also influenced by attention sharing in the auditory modality. In Experiment 3 , the subjects tended to respond "weak" less often when the signal was long rather than short under the half and maximum-attention to intensity conditions. This ef- 
fect suggests that the influence of temporal summation upon perceived loudness (Zwislocki, 1969) is attention dependent.

Finally, temporal discrimination seems to be more resistant to disruption in the auditory modality than when visual stimuli are used. Only the visual modality (Experiment 2) yielded a deficit in temporal performance under the duration-only condition when compared with the out-control condition. This deficit is congruent with the concurrence cost that occurred in the temporal reproduction task of Experiment 1, which was also concerned with visual stimuli.

Regarding Weber's law, the present data remain inconclusive, since the $d^{\prime}$ index in the duration task was higher with the longest duration range in Experiment 2, but not in Experiment 3. In the visual modality, the data might be accounted for by the generalized form of this law (Fetterman \& Killeen, 1992; Killeen \& Weiss, 1987), which adds a constant to the classical Weber fraction in order to account for its increase at low intensities of the stimulus. This constant is assumed to be related to a background sensory noise and is independent of stimulus magnitude.

\section{GENERAL DISCUSSION}

The attentional hypothesis was supported by the main trends observed in Experiments 1-3, in which the subjects' level of attention was directly controlled without changing the task parameters. It was established that controlled attention can be applied to time estimation and has considerable effects on subjective duration in a duration range of .25 to $18 \mathrm{sec}$, and in tasks involving reproduction as well as discrimination of duration.

This conclusion is in line with that from studies by Michon and Jackson (1984; Jackson, 1985, 1990), who were concerned with the issue of automatic versus deliberate processing in temporal tasks. In experiments involving judgments on the order, lag, and position of items in a list, these authors showed that temporal coding is influenced by variables such as the semantics of the material, the level of processing required, the amount of practice, and the stress placed on rehearsal procedures. They also found that individual strategies for performing the task were quite varied and produced varying levels of performance. These results indicate that temporal encoding may, on many occasions, necessitate controlled attention. Thus, "to simply qualify temporal coding as being an automatic by-product is a gross understatement of the possibilities inherent in the processing of temporal information" (Jackson, 1985, p. 189). Three of the criteria proposed by Hasher and Zacks (1979) as attesting to the involvement of deliberate processing were fulfilled in the present experiments: effects of instructions, interference between tasks, and intentional learning. Automatic processing, even though it was not necessarily absent here, is not sufficient to explain that temporal judgments were sensitive to these factors.
Two other questions are raised by the present data. The first concerns the timer concept and the way it may work. The second regards the processes involved in attention sharing.

Michon's (1985) idea that time not only is an explicit attribute of stimuli, but even has a specific representational code, takes one back to the timer hypothesis. The attentional and memory-based models clearly diverge on the question of this hypothetical internal device. Data that show the existence of attention sharing between temporal and nontemporal judgments and, hence, that point to the fact that it is not only possible but also necessary to pay attention to time-in-passing to perform a timing task correctly, do support the timer concept, even though they do not suffice to assess the existence of a timer. Alternative concepts have been proposed by Block and Reed (1978). In their "contextual-change" model, temporal judgments are assumed to derive from the encoded contextual information available in memory. Under retrospective conditions, the encoding of nontemporal information is associated with context changes (in the environment, the subject's emotions, etc.), which may present modifications as a function of time and ultimately underlie temporal judgments. Under prospective conditions, the act of attending to time on many occasions is essential. Each occasion engenders automatic retrieval of the context changes that have been associated with the previous act of attending to time. "Time tags" are thus encoded; each new time tag is integrated in the record of the retrieval act and updates the contents of memory (Block, 1992; Hintzman \& Block, 1971). Temporal judgments are based on an estimation of the availability of these "temporal context changes." As with the timer model, a positive relationship between subjective duration and the amount of attention paid to time may be expected here, since the number of temporal context changes increases the more that one attends to time. However, in this cognitive model, contextual information is basic to prospective as well as to retrospective judgments, even though the nature of this information is somewhat different in each case. No internal pulses are assumed to exist, and the emphasis is placed on the retrieval process.

In the timer concept, attentional processes are of major importance. Subjective duration is not supposed to depend on the information processed by the timer if no attention is devoted to the duration to be estimated. In the latter case, Zakay (1989) suggested that the output of the timer may be eliminated from working memory and may therefore no longer be available at the moment when the temporal judgment is produced. Still, an alternative hypothesis that bypasses the memory assumption may be proposed: Perhaps the timer is not even activated when attentional resources are not allocated to it. In any case, only the prospective method is appropriate to evaluate the functioning of the timer. Whether it is necessary to elaborate an integrative model explaining both prospective and retrospective judgments (Block, 
1992; Zakay, 1993) or, rather, two complementary models accounting for those different conditions remains an open question.

The detrimental effect on temporal processing observed in the present experiments when attention was turned away from the duration task seemed to take place mainly at an early stage, when temporal information is coded in working memory (Fortin, Rousseau, Bourque, \& Kirouac, 1993). In the timer concept, this effect is consistent with the idea that not enough pulses are encoded or that some pulses are rapidly erased; the counter plays the role of a memory buffer. As noted by Estes (1985), long-term retention of temporal information is not very relevant to estimating time under prospective conditions, since the judgment is produced without any delay. In tasks involving the reproduction of duration (as in Experiment 1), several studies have shown that the errors observed arise mainly from the encoding phase rather than from the production phase (e.g., Brown et al., 1992; Brown \& West, 1990; Wilsoncroft \& Stone, 1975). This conclusion is sustained by the consistency of the effects observed, whether the task involved reproduction (Experiment 1) or discrimination of duration (Experiments 2 and 3 ). If an additional number of pulses were lost while the subject reproduced duration in Experiment 1 , this number was likely negligible in comparison with the amount of lost pulses due to interference during encoding. Still, it may have even increased the underestimation obtained.

The source of errors resulting from attention changes in the encoding phase can be analyzed in light of Keele, Nicoletti, Ivry, and Pokorny's (1989) proposition that the oscillator involved can be interrupted and then restarted-for instance, when a pause occurs during the presentation of events with a particular duration. In Experiment 1 , it can be postulated that each word occurrence induced an attentional shift from the timer to other information processors, and that, even if the pulse source itself went on running, the counter was switched off at each attention shift, hence momentarily preventing pulse accumulation. It is also possible that some relevant pulses that had entered the counter were erased thereafter, as the result of a decrease in the level of attention. In Experiments 2 and 3, the discrimination of intensity may have required more attention at the beginning of the stimulus than at its end, as suggested by the subjects' comments and as indicated in Experiment 3 by the fact that the effects of attention on the probability of responding "short" was significant at $250 \mathrm{msec}$ but not at $3,000 \mathrm{msec}$.

The impairment due to attention shifts is possibly more severe in temporal than in nontemporal tasks. Any switch should be detrimental to time estimation, since a duration needs to be measured without interruption from its onset to its end. In contrast, attention switching should be less damaging to nontemporal tasks, since the shifts may occur only when sufficient time has been spent on the information processing, as has been proposed in dual tasks of visual detection (Bonnel et al.,
1987; Navon \& Gopher, 1979). The difference in sensitivity to interference found between temporal and nontemporal tasks in the present experiments may be partly due to this distinct effect of switching.

The existence of switching versus sharing mechanisms in dual-task paradigms is often debated in studies on attention. This topic is typically studied in visual detection tasks, in which proportions of attention are varied between blocks of trials. Within a block that involves unchanging instructions of attention sharing, switching may occur between trials, so that one component of the task is given attention in a certain proportion of trials (for instance, $80 \%$ ) and not in the other ones. In addition, a particular state of shared attention, depending on allocation demands, may be adopted after a switch. Both processes have been found to appear within the same experimental procedure (Sperling \& Melchner, 1978). In the present experiments, each trial was cued differently in order to strengthen the effects of the attention-sharing instructions (cf. Posner, Nissen, \& Ogden, 1978). Within a trial, however, switching and sharing mechanisms could both take place. Here, the question of how the timer may function again arises.

For instance, in Experiment 1, under the condition in which $75 \%$ attention was to be attributed to words, maximal attention may have been directed to a word each time a shift from duration to words took place, but only $75 \%$ of the shifts may have occurred in a series. Alternatively, all the words may have induced attention shifts, but with a prescribed level of attention fixed at $75 \%$. The latter suggestion seems more likely, because the attention shift caused by the occurrence of a word on the screen was probably difficult to prevent. In Experiments 2 and 3, attention shifts between duration and intensity were also supposed to exist. Here we suggested that the time spent processing intensity - that is, the time during which the counter was switched off-relative to the duration of the stimulus determined the amount of temporal underestimation. The duration of a shift might account for the number of pulses lost. This process would not exclude that sharing mechanisms might take place. Sharing mechanisms might determine the probability that some pulses, even though they entered the counter, are erased before the final number of pulses is counted; this probability might increase the more attention to time decreases. The possibility that different conditions induce distinct mechanisms should not be disregarded. This discussion points to the fact that further experiments determining the conditions under which switching and sharing processes take place will also help clarify temporal mechanisms.

The present series of experiments permit us to conclude that, under the prospective conditions of temporal judgments, the amount of attention allocated to time is a key factor of a temporal performance. The allocation of attention to time determines the accuracy of timing as well as the subjective length of the internal duration. The results of all the experiments can be well explained within the internal-timer framework developed in time psycho- 
physics (see, e.g., Church, 1984), a framework with which the attentional model has strong connections. The present work should be considered an effort to integrate two different approaches to time--cognitive and psychophysical (Allan, 1992; Block, 1990; Brown et al., 1992) - that were developed independently, although the ultimate object to be studied-internal time-is the same.

\section{REFERENCES}

Allan, L. G. (1979). The perception of time. Perception \& Psychophysics, 26, 340-354.

Allan, L. G. (1992). The internal clock revisited. In F. Macar, V. Pouthas, \& W. J. Friedman (Eds.), Time, action and cognition: Towards bridging the gap (pp. 191-202). Dordrecht: Kluwer Academic Publishers.

Allan, L. G., Kristofferson, A. B., \& Wiens, E. W. (1971). Duration discrimination of brief light flashes. Perception \& Psychophysics, 9 (3B), 327-334.

BLOCK, R. A. (1989). Experiencing and remembering time: Affordances, context and cognition. In I. Levin \& D. Zakay (Eds.), Time and human cognition (pp. 333-363). Amsterdam: NorthHolland.

BLock, R. A. (1990). Models of psychological time. In R. A. Block (Ed.), Cognitive models of psychological time (pp. 1-35). Hillsdale, NJ: Erlbaum.

BLOCK, R. A. (1992). Prospective and retrospective duration judgment: The role of information processing and memory. In F. Macar V. Pouthas, \& W. J. Friedman (Eds.), Time, action and cognition: Towards bridging the gap (pp. 141-152). Dordrecht: Kluwer Academic Publishers.

BLoCK, R. A., \& REED, M. A. (1978). Remembered duration: Evidence for a contextual-change hypothesis. Journal of Experimental Psychology: Human Learning \& Memory, 4, 656-665.

Bonnel, A. M., PossamaÏ, C. A., \& Schmitt, M. (1987). Early modulation of visual input: A study of attentional strategies. Quarterly Journal of Experimental Psychology, 39A, 757-776.

Brown, S. W., StubBs, D. A., \& West, A. N. (1992). Attention, multiple timing, and psychophysical scaling of temporal judgments. In F. Macar, V. Pouthas, \& W. J. Friedman (Eds.), Time, action and cog. nition: Towards bridging the gap (pp. 129-140). Dordrecht: Kluwer Academic Publishers.

Brown, S. W., \& WEST, A. N. (1990). Multiple timing and the allocation of attention. Acta Psychologica, 75, 103-121.

Casini, L., Macar, F., \& Grondin, S. (1992). Time estimation and attentional sharing (short communication). In F. Macar, V. Pouthas, \& W. J. Friedman (Eds.), Time, action and cognition: Towards bridging the gap (pp. 177-180). Dordrecht: Kluwer Academic Publishers.

Church, R. M. (1984). Properties of the internal clock. In J. Gibbon \& L. Allan (Eds.), Timing and time perception (Annals of the New York Academy of Sciences, Vol. 423, pp. 566-582). New York: New York Academy of Sciences.

Church, R. M., \& Broadbent, H. A. (1990). Alternative representations of time, number, and rate. Cognition, 37, 55-81.

Creflman, C. D. (1962). Human discrimination of auditory duration Journal of the Acoustical Society of America, 34, 582-593.

Divenyi, P. L., \& DanNer, W. F. (1977). Discrimination of time intervals marked by brief acoustic pulses of various intensities and spectra. Perception \& Psychophysics, 21, 125-142.

DuBoIs, D. (1982). Normes de production d'exemplaires appartenant à 22 catégories sémantiques à partir d'une consigne "classique" et d'une consigne d'imagerie (Document 181). Paris: University Paris VIII.

Estes, W. K. (1985). Memory for temporal information. In J. A. Michon \& J. L. Jackson (Eds.), Time, mind and behavior (pp. 151-168). Heidelberg: Springer-Verlag.

Fetterman, J. G., \& Killeen, P. R. (1991). Adjusting the pacemaker. Learning \& Motivation, 22, 226-252.
Fetterman, J. G., \& Killeen, P. R. (1992). Time discrimination in Columba livia and Homo sapiens. Journal of Experimental Psychology: Animal Behavior Processes, 18, 80-94.

Fortin, C., Rousseau, R., Bourque, P., \& Kirouac, E. (1993). Time estimation and concurrent nontemporal processing: Specific interference from short-term-memory demands. Perception \& Psychophysics, 53, 536-548.

Gibron, J., Church, R. M., \& MECK, W. H. (1984). Scalar timing in memory. In J. Gibbon \& L. G. Allan (Eds.), Timing and time perception (Annals of the New York Academy of Sciences, Vol. 423, pp. 52-77). New York: New York Academy of Sciences.

Grondin, S., \& MACAR, F. (1992). Dividing attention between temporal and nontemporal tasks: A performance operating characteristic-POC-analysis. In F. Macar, V. Pouthas, \& W. J. Friedman (Eds.), Time, action and cognition: Towards bridging the gap (pp. 119-128). Dordrecht: Kluwer Academic Publishers.

HASHER, L., \& ZACKS, R. T. (1979). Automatic and effortful processes in memory. Journal of Experimental Psychology: General, 108, 356-388.

Hicks, R. E., Miller, G. W., Gaes, G., \& Bierman, K. (1977). Concurrent processing demands and the experience of time-in-passing. American Journal of Psychology, 90, 431-446.

Hicks, R. E., Miller, G. W., \& Kinsbourne, M. (1976). Prospective and retrospective judgements of time as a function of amount of information processed. American Journal of Psychology, 89, 719730 .

Hintzman, D. L., \& Block, R. A. (1971). Repetition and memory: Evidence for a multiple-trace hypothesis. Journal of Experimental Psychology, 88, 297-306.

JACKSON, J. L. (1985). Is the processing of temporal information automatic or controlled? In J. A. Michon \& J. L. Jackson (Eds.), Time, mind and behavior (pp. 179-190). Heidelberg: Springer-Verlag.

JACKSON, J. [L.] (1990). A cognitive approach to temporal information processing. In R. A. Block (Ed.), Cognitive models of psychological time (pp. 153-180). Hillsdale, NJ: Erlbaum.

JoNES, M. R., \& BoLTZ, M. (1989). Dynamic attending and responses to time. Psychological Review, 96, 459-491.

KAhNEMAN, D. (1973). Attention and effort. Englewood Cliffs, NJ: Prentice-Hall.

Keele, S. W., Nicoletti, R., Ivry, R. I., \& Pokorny, R. A. (1989). Mechanisms of perceptual timing: Beat-based or interval-based judgments? Psychological Research, 50, 251-256.

KilleEN, P. R., \& Weiss, N. A. (1987). Optimal timing and the Weber function. Psychological Review, 94, 455-468.

KINCHLA, R. A. (1980). The measurement of attention. In R. S. Nickerson (Ed.), Attention and performance VIII (pp. 213-238). Hillsdale, NJ: Erlbaum.

KRAMEr, A., \& SpINKs, J. (1991). Capacity views of human information processing. In J. R. Jennings \& M. G. H. Coles (Eds.), Handbook of cognitive psychophysiology: Central and autonomic nervous system approaches (pp. 179-249). Chichester, U.K.: Wiley.

MACAR, F. (1980). Le temps: Perspectives psychophysiologiques. Brussels: Mardaga.

MACAR, F. (1985). Time psychophysics and related models. In J. A. Michon \& J. L. Jackson (Eds.), Time, mind and behavior (pp. 112130). Heidelberg: Springer-Verlag.

MaCAR, F. (1994). Time estimation under prospective conditions: Effects of quantity, complexity and periodicity. Manuscript submitted for publication.

Macar, F., Pouthas, V., \& Friedman, W. J. (Eds.) (1992). Time, action and cognition: Towards bridging the gap. Dordrecht: Kluwer Academic Publishers.

MCClain, L. (1983). Interval estimation: Effect of processing demands on prospective and retrospective reports. Perception \& Psychophysics, 34, 185-189.

MECK, W. H. (1984). Attentional bias between modalities: Effect on the internal clock, memory, and decision stages used in animal time discrimination. In J. Gibbon \& L. G. Allan (Eds.), Timing and time perception (Annals of the New York Academy of Sciences, Vol. 423, pp. 528-541). New York: New York Academy of Sciences.

Michon, J. A. (1972). Processing of temporal information and the cognitive theory of time experience. In J. T. Fraser, F. C. Haber, \& 
G. H. Müller (Eds.), The study of time (pp. 242-258). Heidelberg: Springer-Verlag.

Michon, J. A. (1985). The compleat time experiencer. In J. A. Michon \& J. L. Jackson (Eds.), Time, mind and behavior (pp. 20-52). Heidelberg: Springer-Verlag.

MichON, J. A., \& JACKSON, J. L. (1984). Attentional effort and cognitive strategies in the processing of temporal information. In J. Gibbon \& L. G. Allan (Eds.) Timing and time perception (Annals of the New York Academy of Sciences, Vol.423, pp. 298-321). New York: New York Academy of Sciences.

Navon, D., \& Gopher, D. (1979). On the economy of the humanprocessing system. Psychological Review, 86, 214-255.

Norman, D. A., \& Bobrow, D. G. (1976). On the analysis of performance operating characteristics. Psychological Review, 83, 508-510.

Ornstein, R. E. (1969). On the experience of time. Middlesex, England: Penguin.

Posner, M. I., Inhoff, A. W., Friedrich, F. J., \& Cohen, A. (1987). Isolating attentional systems: A cognitive-anatomical analysis. Psychobiology, 15, 107-121.

Posner, M. I., Nissen, M. J., \& Ogden, W. C. (1978). Attended and unattended processing modes: The role of set for spatial location. In H. L. Pick \& I. J. Saltzman (Eds.), Modes of perceiving and processing information (pp. 137-157). Hillsdale, NJ: Erlbaum.

Posner, M. I., \& Petersen, S. E. (1990). The attention system of the human brain. Annual Review of Neurosciences, 13, 25-42.

Rousseau, R., Picard, D., \& Pitre, E. (1984). An adaptive counter model for time estimation. In J. Gibbon \& L. G. Allan (Eds.), Timing and time perception (Annals of the New York Academy of Sciences, Vol. 423, pp. 639-642). New York: New York Academy of Sciences.
Sperling, G., \& Melchner, M. J. (1978). The attention operating characteristic: Examples from visual search. Science, 202, 315 318.

TANNER, J. A., \& SWETS, W. P. (1954). A decision-making theory of visual detection. Psychological Review, 61, 401-409.

Thomas, E. A. C., \& Weaver, W. B. (1975). Cognitive processing and time perception. Perception \& Psychophysics, 17, 363-367.

Thomas, L. A., \& CANTOR, N. E. (1978). Interdependence between the processing of temporal and nontemporal information. In J. Requin (Ed.), Attention and performance VII (pp. 43-62). Hillsdale, NJ: Erlbaum.

Treisman, M. (1963). Temporal discrimination and the indifference interval: Implications for a model of the internal clock. Psychological Monographs (Whole No. 76).

Wilsoncroft, W. E., \& Stone, J. D. (1975). Information processing and estimation of short time intervals. Perceptual \& Motor Skills, 41, 192-194.

ZAKAY, D. (1989). Subjective and attentional resource allocation: An integrated model of time estimation. In I. Levin \& D. Zakay (Eds.), Time and human cognition (pp. 365-397). Amsterdam: North-Holland.

ZAKAY, D. (1993). Relative and absolute duration judgments under prospective and retrospective paradigms. Perception \& Psychophysics, 54, 656-664.

ZWISLOCKI, J. J. (1969). Temporal summation of loudness: An analysis. Journal of the Acoustical Society of America, 46, 431-441.

(Manuscript received July 26, 1993 ; revision accepted for publication January 10, 1994. 